\title{
Metodologia para adaptação de conteúdo editorial imagético para deficientes visuais
}

\author{
Metodology to adapt editorial imagery content for visually impaired people
}

\author{
Dominique L. Adam, Carolina Calomeno
}

metodologia de design editorial, adaptação inclusiva, deficientes visuais

\begin{abstract}
O objetivo desse artigo é apresentar uma metodologia para adaptar representações gráficas de um produto editorial para crianças com deficiência visual congênita, ou seja, aquelas que já nasceram com a deficiência ou a adquiriram até os cinco anos de idade. As pesquisas teóricas elucidaram o assunto e a pesquisa de campo observacional com as crianças foram imprescindíveis para a efetivação do projeto inclusivo. Utilizando técnicas de produção gráfica diferenciadas e independentes do método braile, o projeto de adaptação inclusiva visa estimular as habilidades sinestésicas necessárias à pré-alfabetização - a partir de pesquisa, identificação e análise de materiais direcionados - através da tradução intersemiótica para posterior adaptação gráfica.
\end{abstract}

editorial design methodology, inclusive adaptation, visually impaired people

The aim of this article is to present a methodology to adapt visual representations of an editorial product for children with congenital visual impairments, those who have been born with visual impairment or its detection occurred until 5 years old. The theorical researches explain the subject and the observational field research with the children were essential to actualize the inclusive project. Using different kinds of graphic production independent of Braille process, this inclusive adaptive design urges to synesthesics' skills needed to literacy from research, identification and analisys of different graphic materials - through intersemiotic translation for graphic adaptation afterwards. In pair with academical researches, the field research was indispensable to conclude this inclusive adaptive design.

\section{Introdução}

A linguagem é um tipo de técnica que pode ter efeitos decisivos na vida do indivíduo e na vida das pessoas a seu redor, sendo necessária para as mais variadas atividades: informar-se, comunicarse, interpretar um poema, ler um livro. Através da linguagem escrita, falada, desenhada é possível adquirir conhecimento, entretenimento e se localizar no mundo. Uma forma de interação entre pessoa-mundo é dada através da leitura, dos livros extensos ou curtos, lúdicos ou sistemáticos os quais são imprescindíveis para a alfabetização. Segundo Richard Bamberger (1994, p. 34), "Se conseguirmos fazer com que a criança tenha sistematicamente uma experiência positiva com a linguagem, estaremos promovendo o seu desenvolvimento como ser humano." De fato a leitura e os livros em geral têm suma importância para o desenvolvimento das pessoas, seja propondo entretenimento ou conhecimento.

A literatura infantil, por sua vez, traz desde cedo a intenção de fazer com que os pequenos seres desbravem o mundo. O livro infantil é utilizado como recurso pedagógico e pode ser um auxílio para compor, enriquecer, constituir bagagem intelectual de cada um. Além de auxiliar na alfabetização, este tem o potencial de despertar curiosidade, auxiliar no processo de captação e comparação de coisas, objetos, pessoas, lugares, etc. Porém, estas peculiaridades que os livros possuem são pouco utilizadas em materiais gráficos destinados às pessoas com deficiência visual.

São necessárias muitas palavras para representar uma ilustração, por exemplo. Como descrever as cores de um arco íris para uma criança que possui deficiência visual? As palavras servem como apoio, mas é necessário proporcionar aos deficientes visuais experiências tão ricas quanto aquelas vividas pelos videntes. 
A partir do contexto apresentado, este texto apresenta um modelo metodológico para adaptação inclusiva e um exemplificado no projeto editorial inclusivo The Black Book of Colors ${ }^{1}$, com foco no usuário e na efetividade da compreensão sensorial, sendo capaz de integrar e estimular as experiências sensoriais das crianças cegas congênitas o mais cedo possível.

Algumas metodologias centradas no usuário, foram estudadas e, de acordo com o contexto, foram adaptadas para melhor colaborar no processo de coleta de informações. O desenvolvimento das pesquisas observacionais, realizadas durante todo o processo, possibilitou projetar um produto editorial destinado às crianças deficientes visuais, tendo como base metodologias de análise centradas no usuário e também a convivência com o público alvo.

Para dar inicio ao estudo, o público alvo foi definido: o material a ser adaptado é destinado às crianças com deficiência visual congênita ou precoce, ou seja, aquelas que nasceram cegas ou adquiriram a doença até os cinco anos de idade. A cegueira, em crianças, provém de anomalias do desenvolvimento, de infecções transplacentárias e neonatais (como exemplo, a toxoplasmose, a rubéola, a sífilis), a prematuridade, os erros inatos do metabolismo, as distrofias, os traumas e os tumores.

A análise da realidade de interação dos usuários com produtos editoriais, entre outras práticas, torna-se imprescindível nesse tipo de metodologia, então no projeto, uma pesquisa de campo foi realizada no Instituto Paranaense de Cegos, localizado em Curitiba-PR, tendo como objetivo principal conhecer o comportamento de uma criança deficiente visual em um ambiente social $-\mathrm{a}$ sala de aula.

Para compreender relação da sociedade perante as pessoas com deficiência visual, foi realizada uma entrevista com o cientista social Manoel Negraes - integrante da equipe de mobilização social da Unilehu - Universidade Livre para a Eficiência Humana, OSCIP Organização da Sociedade Civil de Interesse Público, que atua na área de inclusão social no mercado de trabalho e na sociedade em geral.

Pode-se observar que o preconceito existente é fruto da falta de informação e de uma imagem errônea que a sociedade possui sobre as pessoas que compartilham essa deficiência. Esse fator prejudica o desenvolvimento como ser humano desses indivíduos, dificultando as relações interpessoais. As dificuldades encontradas não se limitam à falta de convívio social. $\mathrm{O}$ acesso aos bens e recursos materiais (lupas eletrônicas, computadores com leitores de tela, etc.) e aos serviços públicos de qualidade dificulta a pessoa com deficiência visual a superar obstáculos para conseguir uma boa educação e colocação no mercado de trabalho.

Os investimentos nessa área ainda são diminutos, já que é necessário que todas as pessoas, independentes de terem problemas de visão ou não, tenham à disposição saúde e educação de qualidade. Como no país ainda há muita desigualdade nesse aspecto, as pessoas com que apresentam alguma deficiência e necessitam de atenção especial, ainda ficam para terceiro plano, pois, mesmo em algumas escolas que já possuem salas com recursos ópticos diferenciados, como as lupas eletrônicas, computadores com leitores de tela, impressoras braile, não apresentam profissionais qualificados para realizar o trabalho de alfabetizar alguém que não enxerga e também, casos em que profissionais estão preparados mais os recursos necessários não estão disponíveis. Para lidar com este problema, a sociedade faz bastante coisa, muitas vezes atua em áreas em que o poder público "abandona ou esquece". Um exemplo a ser citado é o projeto "Ver com as mãos", coordenado pela educadora Diele Fernanda (do IPC Instituto Paranaense de Cegos), que conta com o apoio do Projeto Criança Esperança (Rede Globo e Unesco). O projeto surgiu para estimular as crianças a terem contato com imagens, oferecendo atividades de pintura, desenho e escultura, sem custo, para alunos com limitação visual.

Trabalhos pontuais colaboram tanto na alfabetização de pessoas com a deficiência visual até a reeducação para com o espaço físico, para aqueles que se tornaram cegos, porém sem a ação do Estado, infelizmente não são suficientes para sanar os problemas. O Brasil possui umas das melhores legislações do mundo para quem tem alguma deficiência, porém o governo não assume

\footnotetext{
${ }^{1}$ O projeto editorial do livro The Black Book of Colors, originalmente publicado em espanhol, por Menena Cottin e Rosana Faría, em 2006, propõe a adaptação inclusiva para o repertório do público brasileiro. Neste artigo são apresentados os momentos basilares da pesquisa e as descobertas que fundamentaram o seu desenvolvimento.
} 
seu papel, não aplicando as leis e não fiscalizando seu cumprimento. Dessa forma, o problema persiste, por exemplo: empresas que disponibilizam vagas de emprego destinadas às pessoas portadoras de deficiência - uma ótima ação inclusiva, porém, se o acesso até o local de trabalho continua precário (transporte inacessível, ruas sem sinalização adequada), a inclusão não ocorre. A necessidade da aliança entre governo e sociedade é indispensável para que os problemas possam ser solucionados.

Para que todos esses obstáculos sejam enfrentados pelas pessoas com deficiência visual o convívio familiar é imprescindível. Juntamente com o apoio de bons profissionais, a família pode e deve se tornar a maior aliada da pessoa com deficiência para que esta possa enfrentar as dificuldades e alcançar seus objetivos.

Após essa contextualização sobre a posição do deficiente social no Brasil, foi possível compreender as dificuldades e obstáculos que essa população tem de enfrentar para fazer parte da sociedade. Com isso, uma premissa foi estabelecida: Incluir uma criança deficiente visual na sociedade em que ela vive através da adaptação de materiais de literatura infantil corriqueiros em produtos diferentes na forma de apresentação, rompendo com padrões preestabelecidos e gerando soluções mais criativas abrangendo a tradução intersemiótica ${ }^{2}$ e a sinestesia, ou seja, associando sensações de naturezas distintas com percepções táteis e olfativas.

\section{Metodologia}

Partindo da premissa de desenvolver um produto gráfico voltado as necessidades de usuários tão especiais, observou-se a aderência do modelo centrado no usuário de Frascara, (Frascara, 2004) o qual abrange as etapas de: definição do problema, coleta de informações, definição do problema com base na coleta, definição dos objetivos do produto, especificações e princípios do design e por fim, a proposta de design (conteúdo, forma, mídia, tecnologia), meios de linguagem gráfica foram adicionados, com base em Twyman (1979) e Spinillo (2001) com a intenção de identificar as principais características de materiais gráficos para os usuários pertinentes ao objeto de estudo.

Segundo Frascara (2004), não é fácil estabelecer uma sequência de passos para compor um processo de design devido à variedade de situações onde a comunicação é empregada. Alguns passos podem ser identificados e utilizados como base para a geração de um processo de design. A seguir a sequência e passos apresentados por Frascara, relacionados com a proposta desse projeto editorial inclusivo, e exemplificados na Figura 1.

1. Missão do projeto: primeira definição do problema.

A escassez de materiais gráficos destinados a crianças deficientes visuais.

2. Coleta de informações: sobre o cliente, público alvo e produtos competitivos (se existirem). Pesquisa de campo realizada no Instituto Paranaense de Cegos. Curitiba - PR

3. Segunda definição do problema: análise, interpretação e organização das informações coletadas.

Materiais perceptíveis ao tato e que podem ser utilizados em matérias gráficos inclusivos.

4. Definição dos objetivos: o que o produto deve fazer? Definição dos canais de comunicação, forma de atingir o publico esteticamente e perceptualmente.

Adaptar um livro de história infantil para deficientes visuais através das relações sinestésicas que abrangem o tato e o olfato.

5. Terceira definição do problema: especificação de produção, relacionando os problemas de design com os termos de produção, escrevendo um briefing a respeito.

\footnotetext{
2 Roman Jacobson define tradução intersemiótica como "tradução" que "consiste na interpretação dos signos verbais por meios de sistema de signos não visuais", ou "de um sistema de signos para outro, por exemplo, da arte verbal para a música, a dança, o cinema ou a pintura". Tradução Intersemiótica, Julio Plaza.
} 
Definição dos materiais e técnicas de produção gráfica mais acessíveis à percepção tátil e olfativa, como o relevo resultante da impressão braile e timbragem, aliado ao verniz aromático.

6. Desenvolvimento da proposta de design: considerações sobre forma, conteúdo, mídia e tecnologia.

Estudo do método de representações gráficas utilizado por crianças deficientes visuais congênitas já experientes em desenho.

7. Apresentação ao cliente: um ato informacional e persuasivo

Testagem do material adaptado. Ilustrações selecionadas pela criança deficiente visual como "melhor representação tátil".

8. Organização de produção: preparação para o design final para a produção.

Estudo de formas, tamanhos e espaços necessários para conter as representações gráficas de acordo com o estudo de campo realizado, onde foi possível observar a "área útil" do papel onde a criança deficiente visual realiza suas interpretações gráficas.

\section{Supervisão de implementação.}

Testagem do material adaptado em versão final: livro finalizado, podendo ser lido pela criança deficiente visual sem a ajuda de um vidente.

10. Avaliação da execução: comparação de resultados com os estabelecidos pelo sistema operacional, ajustes eventuais baseados na avaliação e ajustes futuros.

Ajustes necessários em técnicas viáveis de produção gráfica.

Figura 1: O processo de design do projeto, adaptado dos 10 passos de Frascara (1979).

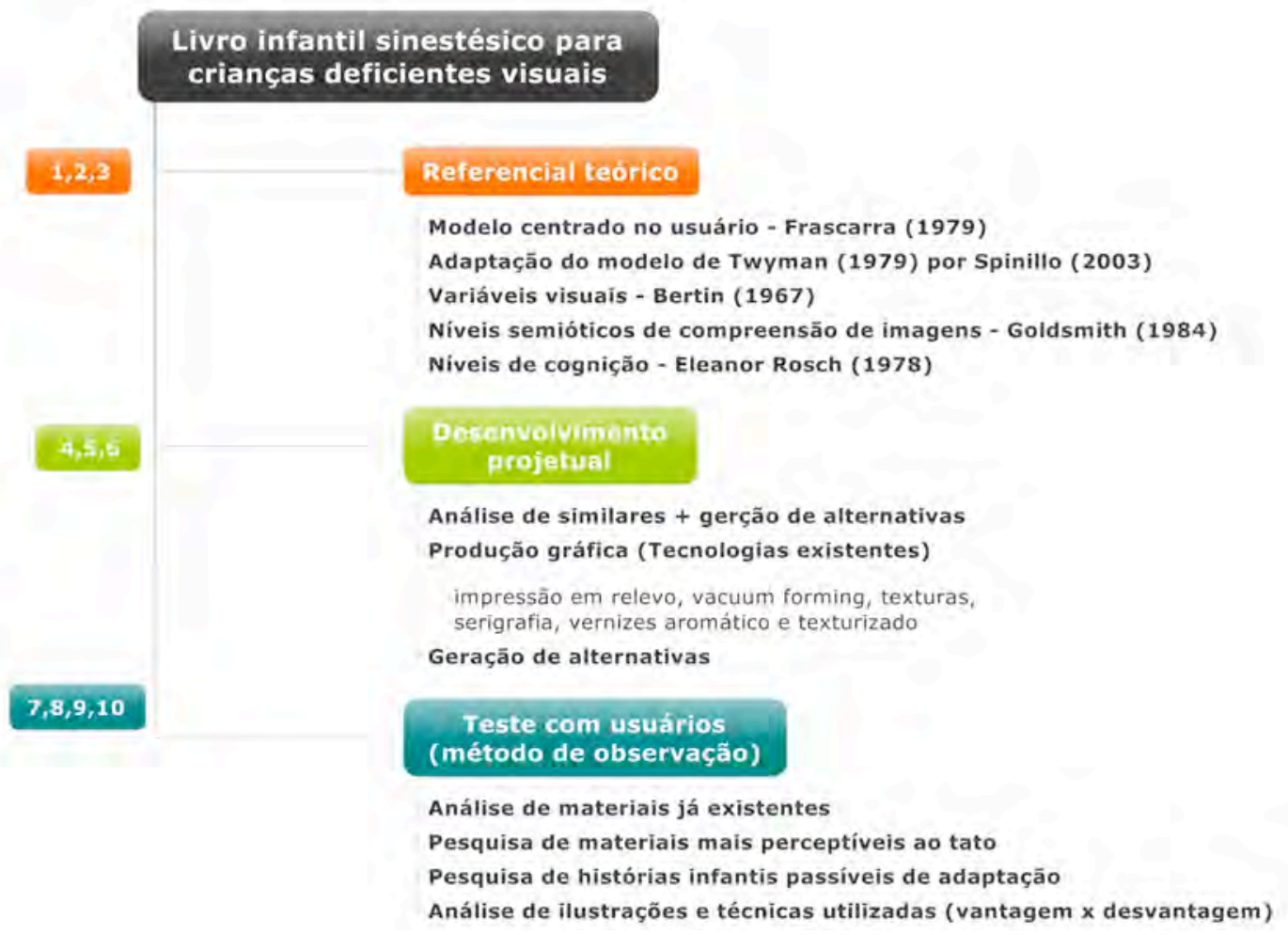

A pesquisa se inicia com o referencial teórico sobre deficientes visuais, o processo de aprendizagem, a importância do livro para este público alvo abordando a literatura infantil. Aspectos de produção gráfica e as tecnologias existentes também são de grande importância para a realização do projeto. 
Após compilação desses dados, o desenvolvimento projetual é iniciado, abordando a seleção de amostragem, com modelo de estutura da linguagem de Twyman (1979) revisto por Spinillo (2001); a análise e complicação de resultados realizada através de modelo de análise baseado em Frascara, (2004); Twyman (1979) e Spinillo (2001).

Figura 2: Modelo de estrutura da linguagem - Twyman (1979).

\section{Estrutura da linguagem (Twyman, 1979)}

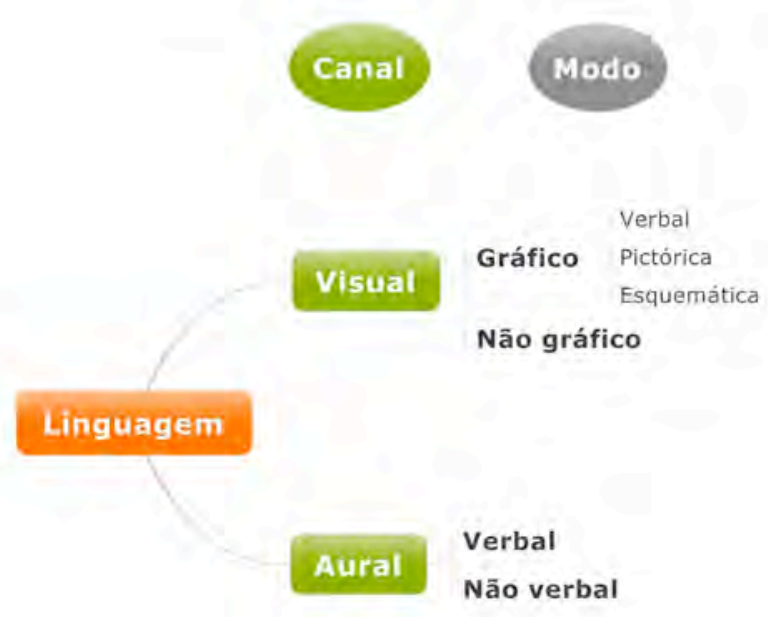

Michael Twyman é um historiador de design que se propôs a tentar resolver algumas das questões da linguagem gráfica direcionadas ao design gráfico. Ele constata que os designers possuem uma percepção diferente das sutilezas da linguagem gráfica e que são capazes de diferenciar a linguagem gráfica verbal da linguagem pictórica. A partir disso, Twyman propôs um modelo capaz de conciliar a visão tradicional da linguística com a visão dos designers.

Neste modelo, a distinção principal é feita através do canal de comunicação. Esta pode ser realizada através da audição ou da visão. Twyman admite que existam outros meios de comunicação, como o tato, para deficientes visuais, porém opta pelas "situações mais comuns em comunicação" (Twyman, 1985).

A partir desse modelo, pode-se observar que a linguagem gráfica pode ser ramificada em três aspectos: a linguagem verbal - é a representação gráfica da linguagem falada; a linguagem esquemática - é formada por formas gráficas que não incluem palavras, números ou imagens pictóricas; e, por fim, a linguagem pictórica comporta as imagens produzidas artificialmente "que remetem por mais remota que seja à aparência ou estrutura de algo imaginado" (Twyman, 1985).

Este modelo foi revisto por Spinillo, 2001 e apresenta a característica tátil. 
Figura 3: Modelo de estrutura da linguagem revisto por Spinillo (2001).

\section{Estrutura da linguagem}

(revista por Spinillo, 2001)

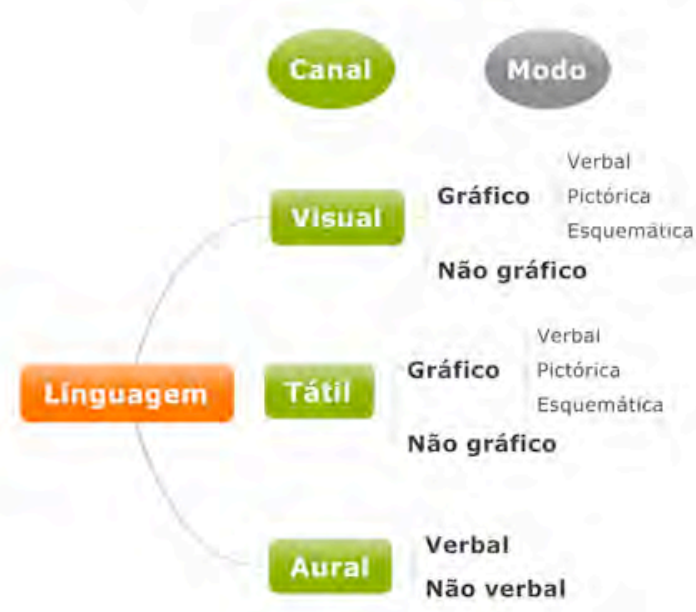

O modelo de análise criado para essa pesquisa foi baseado na seleção de livros infantis direcionados para crianças com deficiência visual e também para videntes. Os similares exploram a produção gráfica que servem como guias da tecnologia utilizada nos métodos de impressão atuais. O modelo foi adaptado tendo como base a estrutura da linguagem proposta por Twyman, 1979 e revisto por Spinillo, 2001, a qual agrega à questão da linguagem visual gráfica as variantes verbais, pictóricas e esquemáticas a partir dos canais da linguagem - visual e tátil.

Figura 4: Modelo de análise criado a partir de Twyman (1979) e Spinillo (2001). 


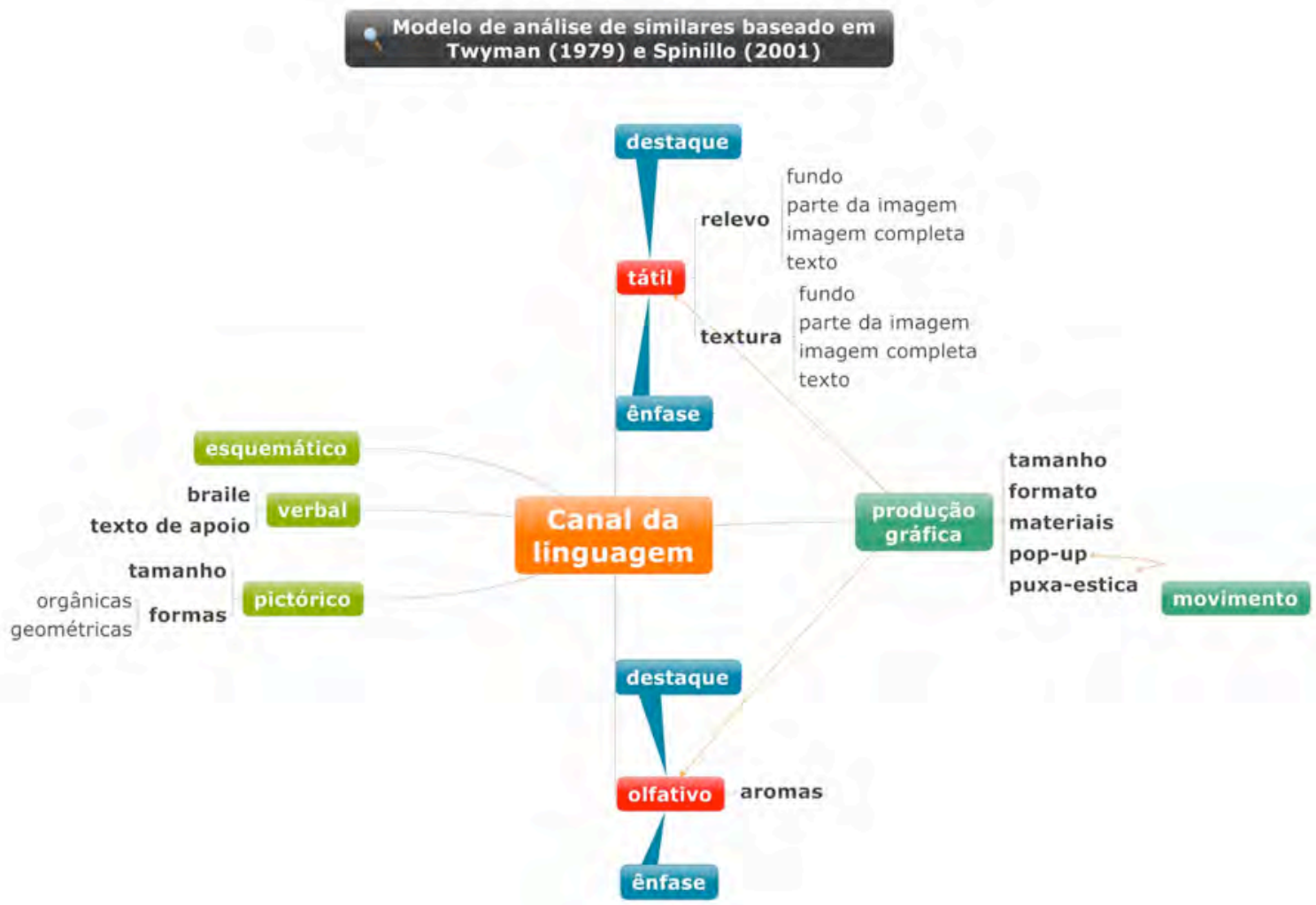

A partir do canal da linguagem, se ramificam os aspectos esquemático, verbal e pictórico. $O$ aspecto verbal abrange os textos em braile e textos de apoio que possam conter no livro. Já o pictórico aborda o tamanho das representações gráficas e suas formas - que foram divididas em orgânicas ou geométricas. A partir disso, os canais tátil e olfativo foram ramificados para análise mais profunda. Esses dois canais possuem as funções de ênfase e destaque. $O$ canal olfativo aborda essencialmente os aromas que alguns livros podem representar através de técnicas de impressão em verniz aromático. O canal tátil abrange os relevos e as texturas.

Relevo ficou definido como contorno de uma representação gráfica e textura como a silhueta que a representação gráfica apresenta. Para esses dois aspectos, quatro características foram apontadas: se possui relevo ou textura como fundo, em parte da imagem, na imagem completa ou se somente o texto é enfatizado por esse aspecto. Todos esses aspectos estão relacionados com a produção gráfica que pode abordar o movimento - no caso de livros pop-up ou puxa-estica. Outros aspectos da produção gráfica como técnicas de impressão, materiais utilizados, formato do livro, tamanho das representações gráficas foram levados em consideração.

\section{Processo de pesquisa de campo}

Frascara (2002) propõe a "desmaterialização do design", com a finalidade de aproximá-lo das ciências sociais, buscando maneiras para tornar a vida das pessoas melhor. Com isso, a importância do estudo do comportamento das pessoas, no contexto em que os objetos e comunicações são utilizados pelas pessoas e seus efeitos sobre elas. É necessário conhecer a sociedade para quem você está criando para que seu produto seja aceito e útil.

Dessa forma, foi realizada uma pesquisa de campo no Instituto Paranaense de Cegos - IPC, localizado em Curitiba - PR para conhecer o público alvo, seu comportamento e suas necessidades.

Essa pesquisa partiu com uma solicitação feita pelo departamento de Design da Universidade Federal do Paraná, para poder realizar a coleta de informações na instituição. Como se trata de um grupo de usuários menores de idade foi anexado um termo de consentimento livre e esclarecido, redigido para os pais das crianças que participariam da pesquisa - um cego precoce (que já nasceu com a deficiência) e outro tardio (deficiência adquirida pós os 5 anos de idade). A 
partir da permissão dos responsáveis desses alunos, as informações começaram a ser coletadas. A pesquisa é qualitativa, abrangendo um público específico que é o de alunos com deficiência visual que já possuem experiência com desenho. Este foi um pré-requisito para o estudo de caso.

Há uma resistência ao realizar pesquisas de campo, principalmente se estas forem realizadas com crianças em instituições especializadas. Algumas dificuldades surgiram ao realizar a pesquisa de campo, porém foram amenizadas devido à disposição de Diele Fernanda, professora de artes do Instituto Paranaense de Cegos, especialista em educação. Ela foi a mediadora entre o contato com a criança com deficiência visual. A partir de suas considerações a respeito do comportamento, da forma de pensar e agir de seus alunos, as perguntas e solicitações foram feitas, em etapas distintas, respeitando o limite individual da criança. Válido ressaltar que toda informação coletada e registrada nesta etapa foi proveniente de dias de pesquisa e convivência com os meninos. Cada momento da pesquisa foi registrado ora com vídeo, ora com fotografia. Conquistar a confiança, a empatia e o reconhecimento dos funcionários e alunos foi um mérito que aqui deve ser mencionado.

O processo de pesquisa (primeira etapa representada pela Figura 1) dentro da instituição durou cerca de seis meses e foi realizado diante a observação da educadora Diele, durante as aulas de artes. A primeira visita à instituição ocorreu para conhecer como é o ambiente direcionado para deficientes visuais realizarem as aulas de artes. Foi possível observar que é um local de fácil deslocamento, com cadeiras, mesas e vários tipos de materiais destinados ao desenho: papel branco de alta gramatura, lápis de cor, giz de cera, alfinetes, base de borracha e objetos com silhueta.

Figura 5: Sala de artes, IPC (fonte: autora)

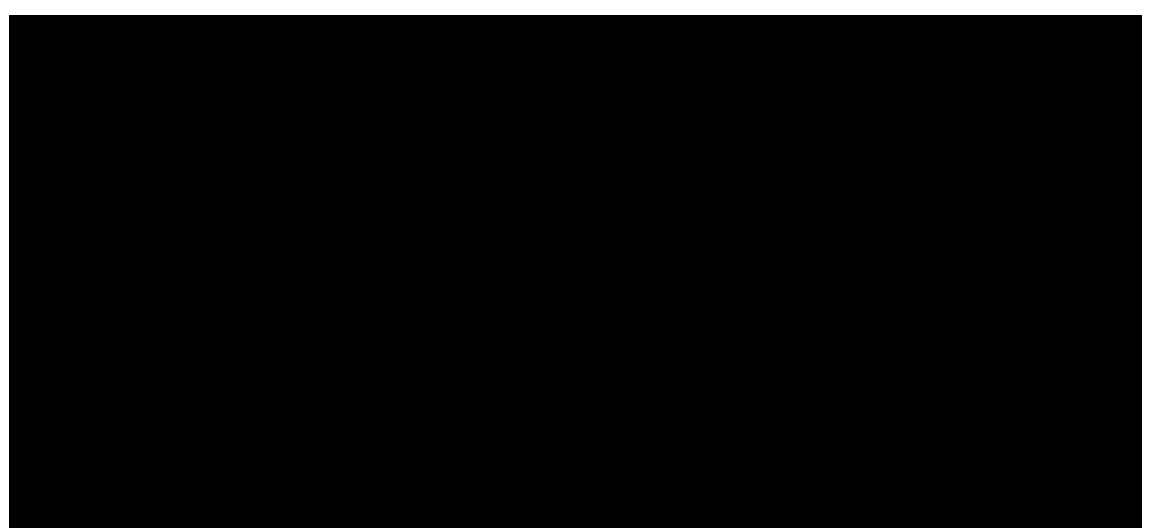

Neste primeiro momento, uma conversa com a educadora a respeito de materiais gráficos destinados a deficientes visuais foi pautada, mostrando sua opinião sobre os tipos de materiais e técnicas de produção gráfica existentes e viáveis que podem ser utilizadas para compor um projeto de design gráfico inclusivo.

Acabamentos gráficos, por exemplo, podem incrementar o aspecto visual de um projeto. Porém, para ser acessível a aqueles que dispõem somente da percepção tátil, são necessárias algumas considerações a respeito de como um indivíduo cego compreende uma imagem, para assim representar, através de acabamentos gráficos perceptíveis ao tato, as informações de forma simplificada e tatilmente compreensíveis.

Em um segundo momento, o livro The Black Book of Colors, de Menena Cotin e Rosana Faría, que foi o vencedor do Prêmio Novos Horizontes 2007 na Feira do Livro de Bolonha, foi apresentado à criança (terceira etapa representada pela Figura 1). O livro é todo preto, com ilustrações em verniz incolor de médio relevo, texto em branco, e em braile - neste caso, a história foi contada verbalmente em português. A história é a sobre a percepção de uma criança cega em contato com o mundo. As representações gráficas não foram de fácil entendimento. Apenas duas das representações, juntamente com a descrição verbal, foram interpretadas pela criança. O livro não é destinado à pessoas com deficiência visual, mas pretende simular a relação do cego com o 
mundo. Da forma em que é apresentado, é visualmente atraente, porém não mostra a realidade da pessoa com deficiência visual.

Figura 6: Análise do contato da criança com o livro The Black Book of Colors. (fonte: autora)

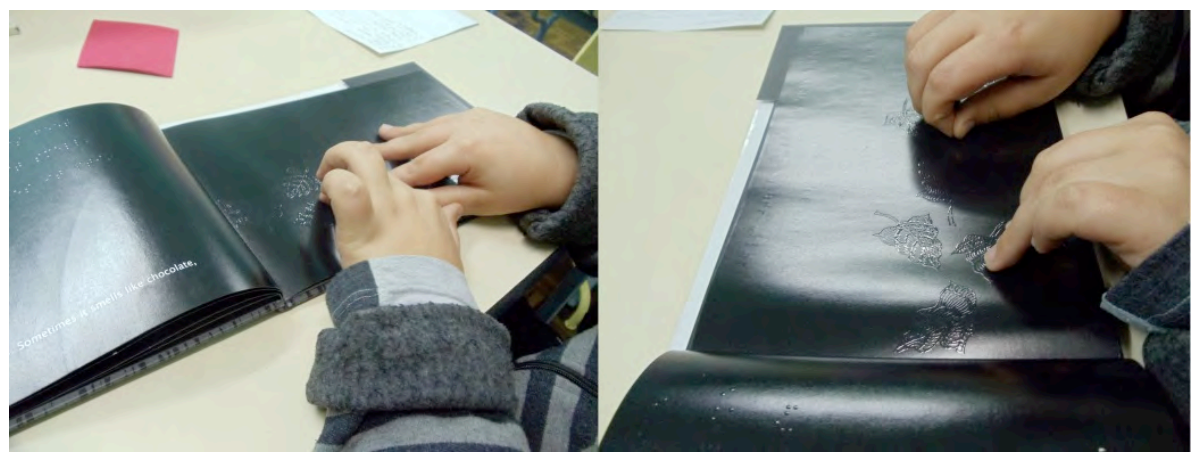

Para entender a maneira que a criança deficiente visual compreende a superfície dos objetos, vários papéis com texturas diferenciadas foram mostrados a dois alunos do IPC e estes fizeram suas considerações e associações entre textura e sensações, de acordo com o repertório de cada um.

Figura 7: Teste de percepção com papéis texturizados. (fonte: autora)

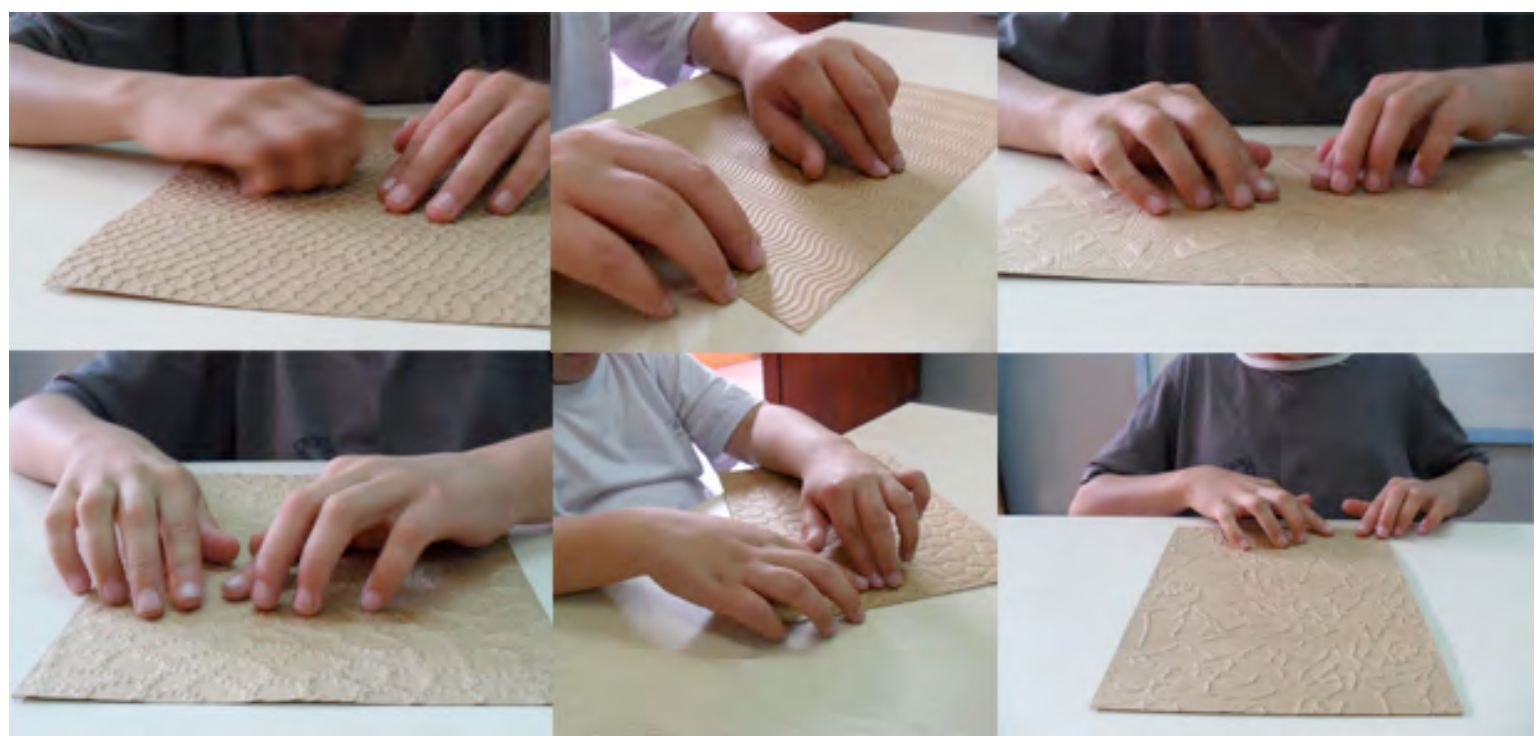

Para compreender melhor o comportamento das crianças com deficiência visual em sala de aula, e também como são os desenhos de crianças cegas, foram observadas algumas atividades durante as aulas de artes do Instituto Paranaense de Cegos.

Em semanas distintas, foi observado o método de desenho da criança, bem como suas referências imagéticas provenientes da descrição verbal que fora aprendendo sobre as coisas. Dessa forma, foi possível constatar que a ilustração do deficiente visual congênito, que já é familiarizado com o desenho é muito objetiva. As representações gráficas são descritas através da linha de contorno e não pela "massa visual".

A relação entre desenho infantil e processos cognitivos está presente desde os primórdios dos estudos referentes a essa prática infantil. Georges-Henri Luquet apud Duarte, entre os anos de 1910 e 1930 dedicou-se ao estudo da arte pré-histórica e primitiva e também ao estudo do 
desenho infantil analisando, em especial, os desenhos de seus filhos. $O$ pesquisador percebe $o$ desenhar como "um ato de representação da realidade".

Em seu primeiro texto sobre desenho infantil "Sur lês debuts Du dessin enfatin" (1910), o autor classifica, em um primeiro momento, o desenho infantil como:

1. Imitação à escrita - traçar linhas no papel.

2. Analogias visuais - identifica semelhança entre as linhas grafadas e determinados objetos.

3. Desenho propriamente dito - o qual a criança se esforça para estabelecer semelhanças entre seu desenho e um objeto qualquer. Após essa análise, Luquet nomeia o desenho infantil como "realismo lógico" em oposição ao "realismo visual", este representando o desenho de adultos. É valido ressaltar que o autor se refere à qualidade do desenho ser análogo a um objeto e não a concepção de representação ideal. Sua ideia de realismo opõe-se às concepções de esquematismo e idealismo. Desta forma, afirma ser necessária a presença mental de um "modelo interno", isto é, a memória de um modo específico utilizado para desenhar esse ou aquele conjunto de objetos (por exemplo: a figura humana e suas variáveis).

\section{Segundo Luquet,}

"Todo desenho é a tradução gráfica da imagem visual que forneça o motivo apresentado e, acreditamos, de uma imagem visual mais ou menos nítida realmente presente no espírito do desenhista no momento que ele desenha, o que nós denominamos modelo interno. Qualquer que seja o ponto de vista subjetivo, do ponto de vista objetivo o desenho é incontestavelmente a tradução gráfica dos caracteres visuais do objeto representado; isto é, tomando emprestado dos estudiosos da lógica o termo "compreensão" pelo qual eles designam o conjunto de caracteres de um objeto, o desenho de um motivo pode ser definido como a tradução gráfica da compreensão visual desse motivo".

Analisando a Figura 8, pode-se notar a diferença da representação se comparada com os modelos mentais de figura humana que possuímos; sejam eles os famosos "bonecos palito", pictogramas, ou ilustrações mais elaboradas. O diferencial neste desenho, e o mais instigante, é que o círculo superior representa a cabeça, diferentemente das imagens mentais que possuímos as quais não representam a cabeça separadamente do rosto, ou seja, o "realismo visual" que representa cabeça como uma unidade completa (com olhos, nariz e boca) o que é diferente do "realismo lógico" o qual representa a cabeça como o topo e unidade separada do que vem a seguir, o rosto.

Figura 8: Representação gráfica de figura humana realizada por uma criança deficiente visual congênita.
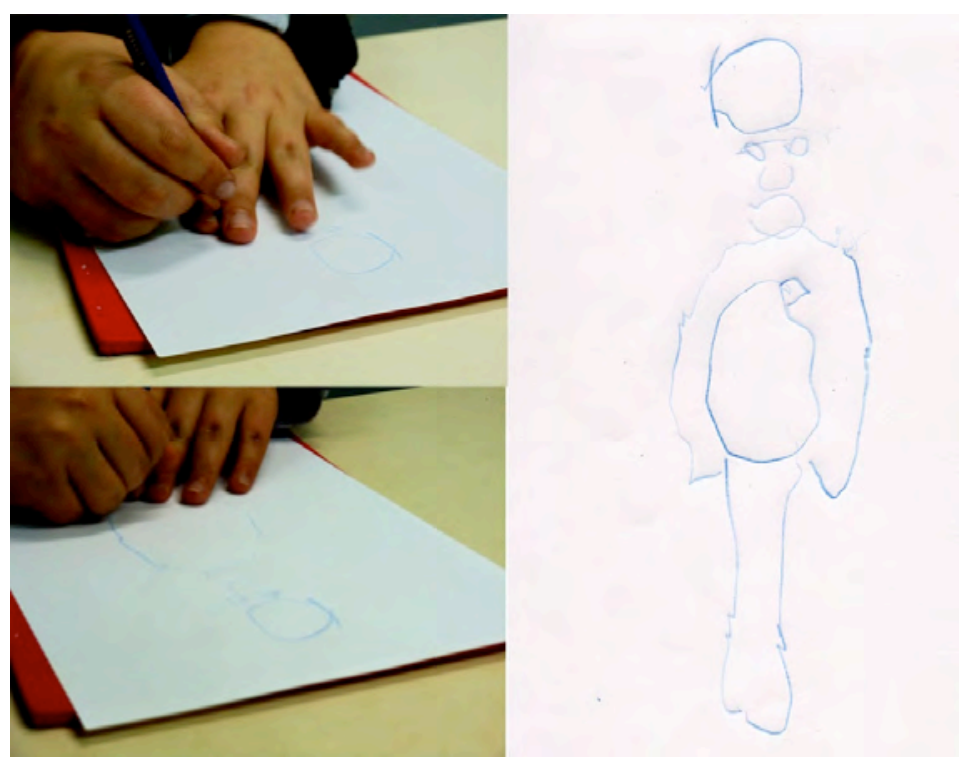
Esta representação foi realizada na sequência em que a criança com deficiência visual tateiase: primeiro toca a cabeça, após os olhos, nariz e boca, em seguida pescoço, tronco e membros. Importante ressaltar que o relato verbal por ela feita durante a representação foi relevante para a compreensão de seu modo de pensar e de realizar as atividades.

Ainda durante a pesquisa de campo, foi solicitado que um menino deficiente visual congênito desenhasse um ônibus (Figura 9). O veículo é utilizado diariamente pelo menino, na ida e volta da escola, logo há familiaridade entre eles. Bruno desenha o veículo utilizando a técnica de punção e, através de linhas, reproduz o objeto 3D (ônibus) de uma forma planificada, representando o espaço interno do ônibus, o espaço por onde ele caminha e tem conhecimento da existência de bancos e uma área específica para o motorista. As rodas do veículo não foram representadas, pois, segundo ele, ele não as "enxerga" de dentro do ônibus.

Figura 9: Representação gráfica de um ônibus realizada por uma criança deficiente visual de 11 anos.

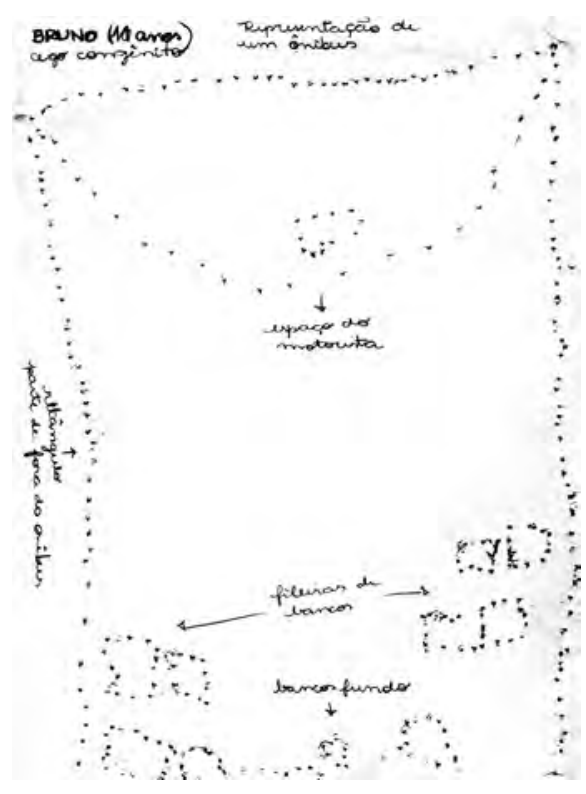

Figura 10: Representação gráfica de um ônibus feita por uma criança vidente, de 11 anos. 


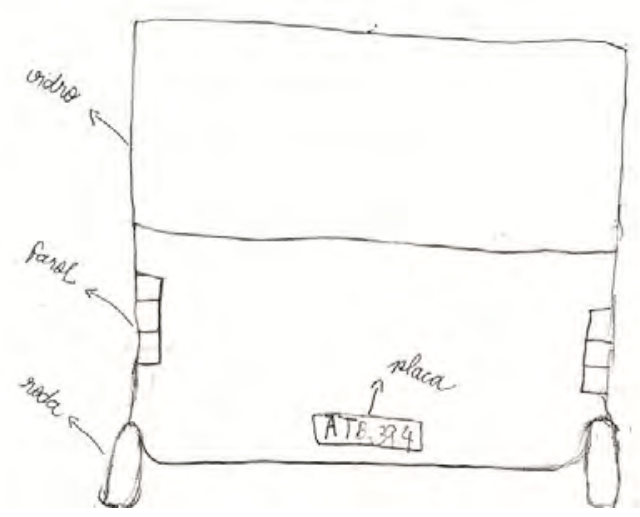

Após essas observações, o foco voltou-se para o tipo da ilustração que é compreensível para o deficiente visual. Com o objetivo de adaptar um livro inclusivo de literatura infantil para deficientes visuais, e também videntes, a proposta foi refazer as ilustrações de acordo com o repertório imagético de Bruno, a criança que participou de todas as fases do projeto.

Conforme suas descrições e associações foi possível caracterizar objetos através de sua cor e formato, remetendo a alguma sensação através da sinestesia: relacionando aromas com as cores, com as diversas superfícies existentes e também com a memória somatossensorial da criança.

Foi possível observar que as pessoas com limitações visuais também podem compreender representações gráficas sem dificuldades. Para isso, é necessário que estas sejam representadas de forma clara e objetiva, sem muitos detalhes visualmente atrativos que se tornam tatilmente confusos. As imagens devem conter elementos caracterizadores e podem ser representadas no papel através do relevo (alto ou baixo) realizado através de impressão e/ou acabamentos gráficos como o verniz, relevo seco e timbragem. É importante salientar que a quantidade de detalhes em uma representação gráfica influencia muito no momento em que o cego vai compreender a imagem. Muitos detalhes juntos e sobrepostos confundem o entendimento da representação gráfica pela pessoa com deficiência visual. Objetividade e clareza devem ser levadas em consideração no momento de realizar ilustrações para esse público alvo. Enfatizar as linhas de contorno de determinado objeto é imprescindível para a compreensão, pois o cego não utiliza o plano, não desenha por massa. A linha é a maior aliada para a sua representação gráfica.

A partir dessas considerações provenientes da pesquisa de campo, alguns princípios foram criados para serem seguidos no momento de geração de alternativas para um projeto editorial inclusivo (segunda etapa representada pela Figura 1), em especial as representações gráficas, as ilustrações:

- devem ser simples e compostas somente por linhas e pontos (sem preenchimento);

- precisam conter elementos caracterizadores;

- de forma alguma podem estar sobrepostas;

- podem variar de tamanho e posição;

- nunca devem variar na quantidade de elementos. Por exemplo, um morango de uma página do livro não pode ser esteticamente diferente se comparado ao de outra página.

Importante salientar que não existem métodos ou instruções consolidadas no Brasil para que guie o designer a gerar um projeto inclusivo. As informações adquiridas durante o processo de pesquisa são exclusivas deste esse projeto, em especial. Todas as relações aqui apresentadas vêm do repertório imagético de uma criança deficiente visual congênita a partir de associações provenientes de informações adquiridas. 


\section{Desdobramentos da pesquisa}

Diante dos princípios resultantes da pesquisa, desenvolveu-se o projeto de adaptação o livro infantil "The Black Book of Colors" ${ }^{3}$ voltado tanto para crianças cegas quanto para videntes.

O processo de ilustração iniciou-se com a pesquisa de campo e ao decorrer da pesquisa, foram testados diferentes tipos de técnicas para simular a impressão em relevo (com verniz e timbragem).

O primeiro teste foi utilizar a cola colorida para conseguir o relevo necessário. Porém não é possível ter um controle ao pressionar o tubo de cola e desenhar. As imagens ficam irregulares e muito tempo é gasto para a finalização.

A segunda tentativa foi bolear as ilustrações com uma caneta sem tinta em um papel de alta gramatura. $\mathrm{O}$ relevo obtido ficou semelhante ao relevo seco, porém ainda não ficou saliente o suficiente para ser perceptível ao tato, pois é difícil manter o controle da pressão da mão sobre o papel.

A terceira tentativa e a selecionada para realizar os testes de compreensão com o usuário foi a ilustração em papel vegetal 90 gramas boleada com a caneta sem tinta. O relevo ficou bem saliente perceptível ao tato. Desta forma, foi possível representar fielmente uma técnica de impressão em larga escala e fazer a validação do material.

Figura 11: Teste de alternativas de representações gráficas de morango e folha seca.
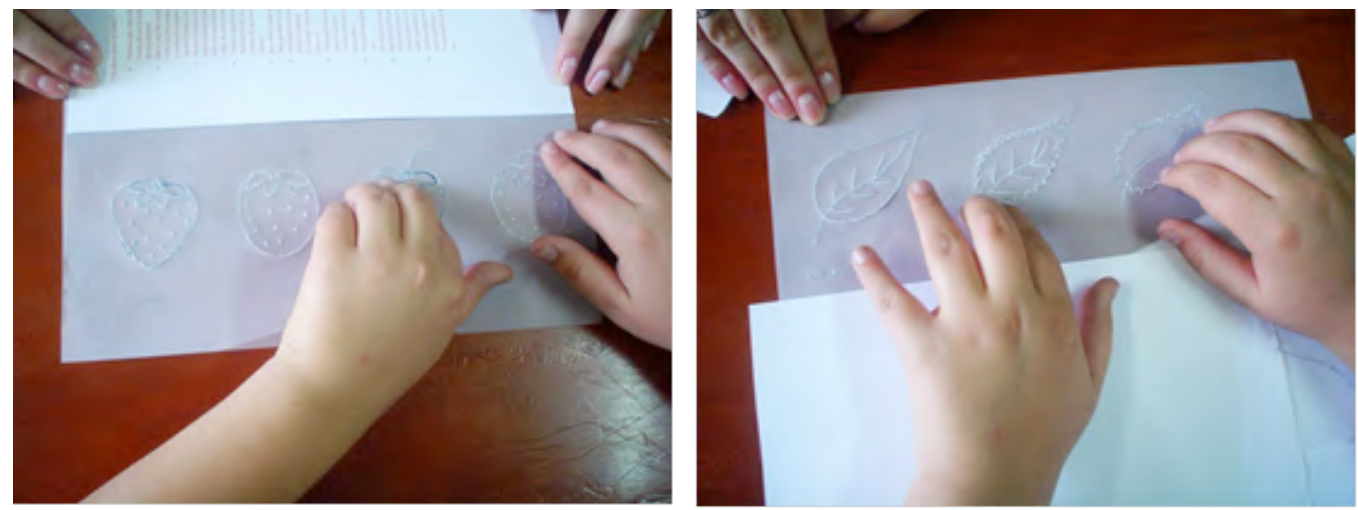

Figura 12: Teste de alternativas de representações gráficas de pipa e água.

${ }^{3}$ A adaptação do livro foi resultado de um Trabalho de Conclusão do Curso de Design - UPFR, vencedor do Prêmio Bom Design 2012. Mais informações e detalhes sobre o projeto podem ser encontrados nos artigos publicados nos Anais do Ergo Design 2012, Anais do P\&D Design 2012 e também na biblioteca do setor de humanas, da Universidade Federal do Paraná. 

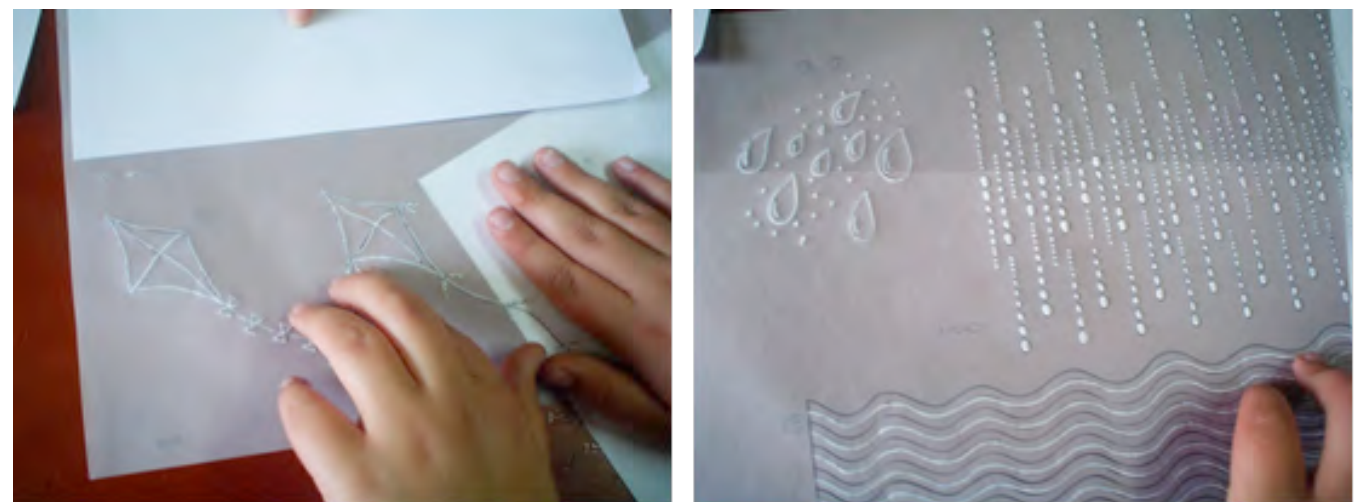

Após os testes de validação das imagens do livro, as mesmas foram dispostas em um layout que simulasse as páginas do livro, para um segundo teste de compreensão. Depois de realizada essa segunda validação, os ajustes necessários foram realizados e um boneco do livro foi confeccionado, conforme Figuras 13 e 14.

Figura 13: Boneco do livro adaptado.

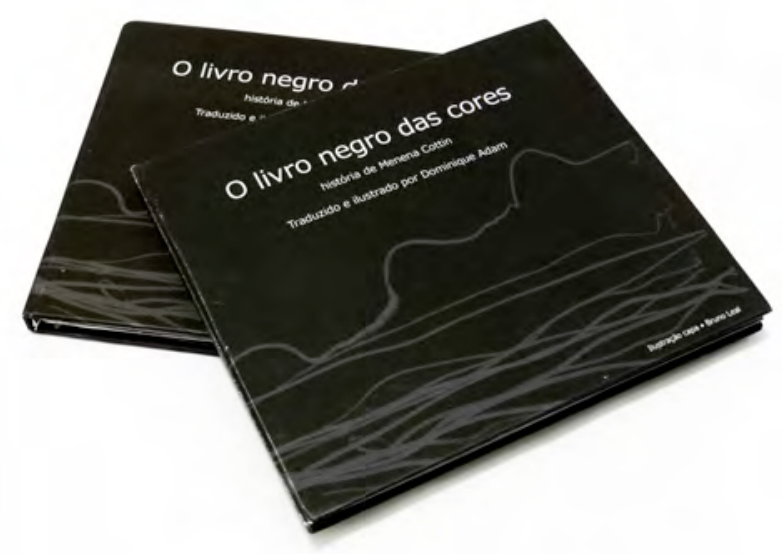

Figura 14: Páginas internas.

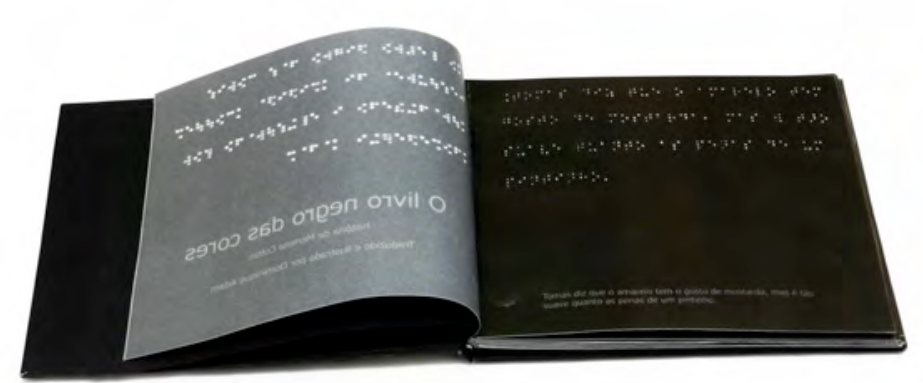



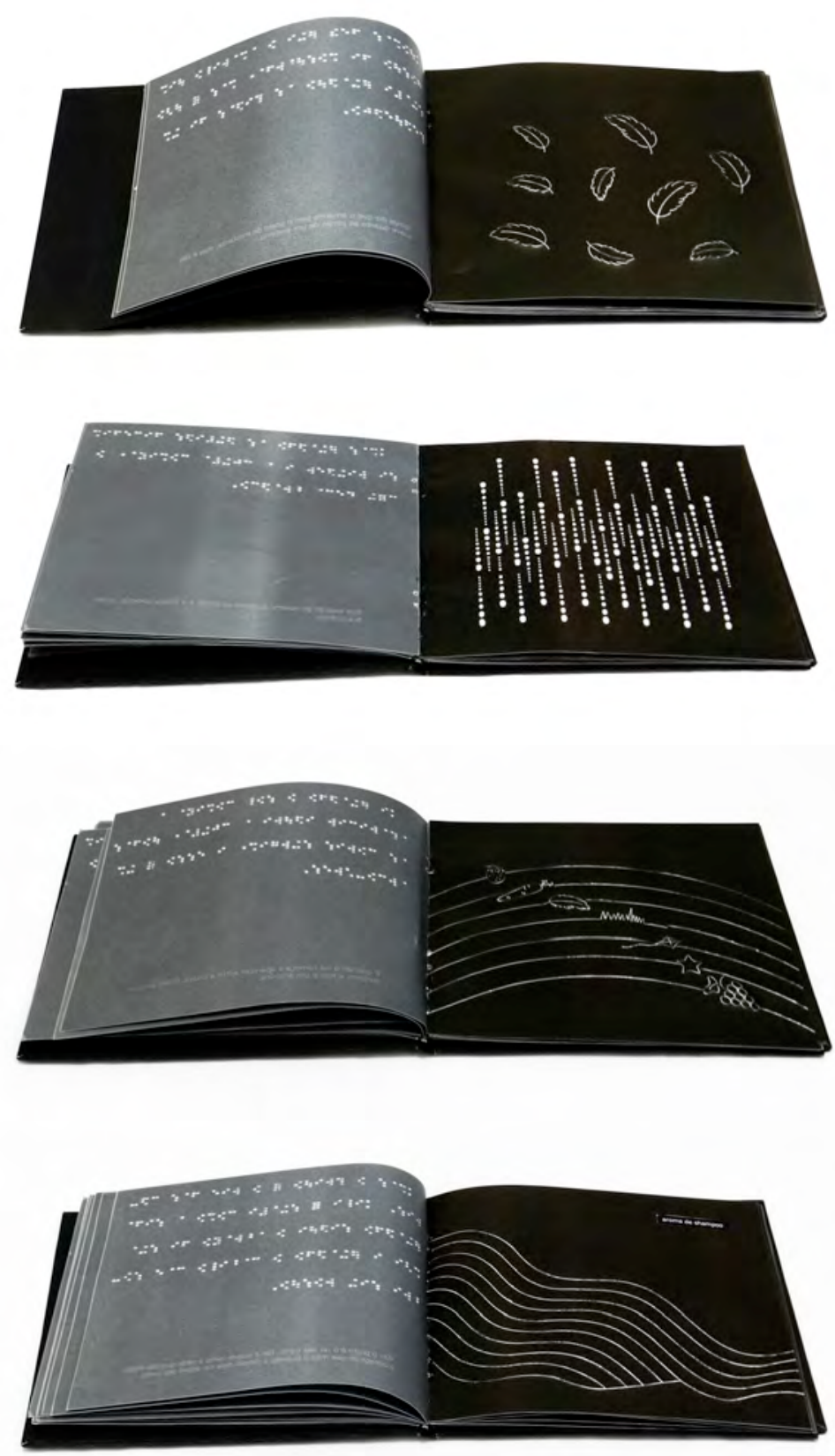

\section{Considerações finais}

A metodologia de design centrada no usuário aplicada a um projeto editorial inclusivo mostrou-se ideal para de atender as características e necessidades perceptivas das crianças com deficiência visual. O contato com o usuário, na observação e validação das representações gráficas adaptadas, foi fundamental para gerar os princípios projetuais que nortearam o desenvolvimento do projeto, em sua fase posterior. Por fim, com este artigo desejamos despertar o interesse de outros designers para também pesquisarem e criarem produtos para deficientes visuais, visto que há pouquíssimos materiais destinados a esse público, pois incluir deficientes visuais no mundo das representações gráficas, é proporcionar o conhecimento e a sensação de liberdade conquistada ao estarem em contato com um material gráfico impresso podendo dizer: eu compreendo! 


\section{Agradecimento}

Toda a pesquisa realizada, os resultados obtidos e o conhecimento apreendido é fruto de uma convivência de aproximadamente sete meses com uma criança deficiente visual congênita, do Instituto Paranaense de Cegos. O maior agradecimento aqui é para Bruno, esse menino de ouro que pode ensinar como é possível se comunicar com representações gráficas sem o auxílio da visão.

\section{Referências}

BERTIN, J. Semiologie graphique: les diagrammes, les rseaux, les cartes. Mouton and GauthiersVillars, The Hague, Paris, 1967.

FRASCARA, Jorge. Communication design: principles, methods, and practice. Allworth Press, New York, 2004.

GOLDSMITH, E. Research into illustration: An approach and a review. Cambridge: Cambridge University Press, 1984.

SPINILLO, C. Linguagem gráfica. Notas de aula da disciplina de Linguagem gráfica pictórica. Departamento de Design; Universidade Federal do Paraná, 2009.

TWYMAN, Michael. Using Pictorial Language: a discussion of the dimensions of the problem. In Designing Usable Texts, (Eds, Thomas Duffy \& Robert Walker), Academic Press, Orlando, 1985.

\section{Sobre as autoras}

Dominique Leite Adam, graduada em Design gráfico pela Universidade Federal do Paraná, possui um projeto de pesquisa para mestrado voltado ao design inclusivo, como continuidade do seu trabalho de conclusão de curso que foi premiado com o Prêmio Bom Design e que representou a Universidade Federal do Paraná, no Köln Design Preis / Alemanha em 2012. Possui publicações na área de design inclusivo e usabilidade.

<domiadam@gmail.com>

Carolina Calomeno, doutoranda em Comunicação pela Unisinos, atua como docente no departamento de Design da Universidade Federal do Paraná, tem pesquisas na área de design de interação, de design adaptado e inclusivo em produtos digitais e editoriais, de design instrucional para objetos de aprendizagem e infografia.

<carolcalomeno.ufpr@gmail.com>

[Artigo recebido em dezembro de 2012, aprovado em dezembro de 2012] 